\title{
Smart Cities for Sustainable Development in India: Opportunities and Challenges
}

\author{
Vaidehi Daptardar ${ }^{1}$ and Manasi Gore ${ }^{2}$
}

\section{Changing Paradigms of Development}

\subsection{Economic Development}

Economic Development is an evolutionary concept and has undergone changes from time to time, so far as its meaning, contents and scope are considered. Traditionally, it has been considered as the process bringing about change in the national income along with changes in the structure of various sectors of the economy. So it is essentially related to analysis of social, economic and political progress of colonial countries on the lines of West Countries after industrial revolution. Thus it is related to the structural changes in the economy and generation of Income and wealth. Adam smith's 'Wealth of Nations' is considered as the first treatise on development. However the systematic study of development started only after realization of the problems of less developed countries in the middle of twentieth century. Development therefore, emerged as a relative concept which presupposed a comparison of less developed countries of Asia, Africa and Latin America with the developed countries of the world. Thus, there has been a shift in the ideological approach of looking at the progress in society. Initially the economic development and progress could be measured in terms of Per Capita Income, GNP and growth in Factors of Production. The invention of machine led to increase in productivity and material welfare was the scope of economic growth. It was Karl Marx who propounded the theory of class struggle amidst development to ultimately end the exploitation of labour. After the Second World War, J.M. Keynes rejected Smith \& Ricardo's development concept and stressed that increase in population in fact stimulates investment ultimately leading to economic growth. In the middle of the last century, Joseph Schumpeter highlighted the role of entrepreneur in introducing innovation for economic development.

The decades of $60 \mathrm{~s}$ and $70 \mathrm{~s}$ of the 20th century were treated as the development decades with $6 \%$ growth of GNP. However it was realized that the problems of poverty and unemployment became the most crucial problems of income distribution and therefore, economic development was to be redefined in terms of elimination of poverty, inequality and unemployment within the context of growing economy.

\subsection{Social Development Perspective}

Social development is a broad concept which refers to development of the society as a whole, which not only adopts itself to the changes but also easily adapts innovation for moving on the new path of development. The concept of Social 
Development has relevance in Population Policy, policy related to urbanization, Industrial location, environmental pollution, regional development, income distribution and governance and administration. In fact, social development consists of all non economic factors, the development of which is a precondition for economic development.

\subsection{Sustainable Development Perspective}

By the end of 70 s of the last century, it was realized the nature and extent of development, as conceived and being perceived would harm more than help the mankind. The cruel exploitation of the natural resources reduced them to a lamentable level. In 1976, the UN Conference on Human Settlement (Habitat I) adopted Vancouver Declaration accepting urbanization as a problem which ought to be contained by promoting rural development and lowering rural urban disparities. The outcome of this Habitat I was establishment of UN Center for Human Settlements (UNCHS) in 1978. Five years later, UN General Assembly appointed the World Commission on Environment and Development (WCED) which presented its Report named 'Our Common Future', also known as Brundtland Report in 1987. It took a more proactive stance on the urban challenge and continued the Habitat II and III to address the issues of 'adequate shelter for all' and 'Sustainable Human Settlements'. The backwash effects of the blind race for development emerged in the form of ecological imbalance, environmental degradation and pollution of water and air along with potential crisis of energy. It was the realization of 'Limits to Growth' that led the 'Green Movement'; and the concept of Sustainable Development gained much significance.

According to 1987 Brundtland Report of the United Nations' World Commission on Environment and Development (WCED), "the development that meets the needs of the present without compromising the ability of future generations to meet their own needs is termed as sustainable development. It means building our communities so that "we can all live comfortably without consuming all of our resources. Living in a sustainable way means leaving more of things we all need to share, like water, energy, clean air and forests, for future generations. Sustainable development is not just about conserving our resources: it is about changing our culture to make conservation a way of life." According to Martin Burian, a broader approach is needed in order to reflect all effects; development needs to be contextualized. A widely accepted and used approach to specify and operationalize the concept of sustainable development is to group Foci of Impact to three categories:

- Ecological/Environmental aspect e.g. improvement or maintenance of life supporting systems

- Social aspects e.g. improvement or maintenance of social living conditions

- Economic aspects e.g. improvement or maintenance of economic capital.

Thus the three pillars of sustainable development are inter-linkages, intergenerational equity, and dynamic efficiency. 


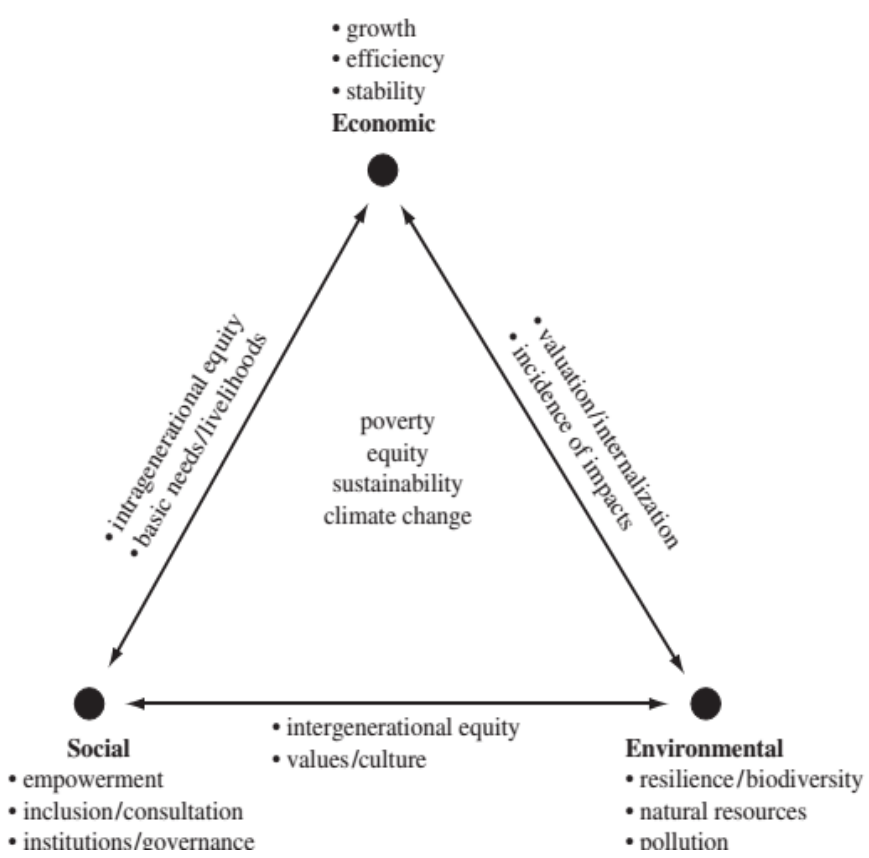

Figure 1:

- inclusion/consultation

Source: Munasinghe(1995)

\subsection{Human Development Perspective}

Although the concept of human development has its origin in the writings of early economists including Robert Lucas, Malthus and J S Mill etc.; it was only in 1990s that United Nations Development Program (UNDP) revived the concept in its Human development Report of 1990. Human development essentially refers to improvement in the overall human well being and quality of life. The UNDP therefore introduced the concept of Human Development Index (HDI) to measure the level of Human Development. It was at the hands of Amartya Sen, the work on Capabilities and Functioning actually shaped the concept of HDI. It was Michel Todaro who emphasized on radical changes in institutional, social and administrative structures as well as people, attitude, customs and beliefs as an essential feature of development.

\section{From Millennium Development Goals (MDGs) to Sustainable Development Goals (SDGs)}

At the dawn of new millennium, the UN hosted Millennium Summit on $8^{\text {th }}$ September 2000 which came out with 8 goals called as 'The Millennium Goals'. The MDGs, their related targets with indicators provided a framework for planning policy intervention and benchmark to monitor progress in Human Development and Poverty Reduction. The MDGs had the target year as 2015 and the Sustainable Development Goals (SDGs) came in 2015 to accelerate the progress achieved under the MDGs and also to address other important development issues. Each of the Sustainable Development Goal is important. 
The SDGs are a proposed set of global development targets to be adopted by governments around the world. There are currently 17 goals with 169 indicators that will define the global sustainable development agenda post-2015. Spearheaded by the United Nations, the SDGs approved in September 2015 at the UN Summit have replaced the Millennium Development Goals (MDGs). The MDGs led to unprecedented progress in certain areas but fell short of transforming societies, as they were focused solely on poverty alleviation in the developing world. The SDGs, on the other hand, will be globally relevant and present a holistic approach to progress by embracing economic, social and environmental dimensions. As governments gear up to sign the SDGs, key roles will be carved out for multiple stakeholders, including society and businesses.

For sustainable development to be achieved, it is crucial to harmonize three core elements: economic growth, social inclusion and environmental protection.

Three key characteristics of the SDGs are:

Universal: global goals set for the "World we want", applicable to developing and developed countries.

- Indivisible: cannot be positioned in a hierarchical or prioritization order. Denial of one invariably impedes enjoyment of other rights and basics needs.

$>$ Transformative: Transforming current challenges into opportunities for the 5P (peace, people, planet, prosperity and partnership). These Five Pillars of Sustainable Development are shown in the following figure:

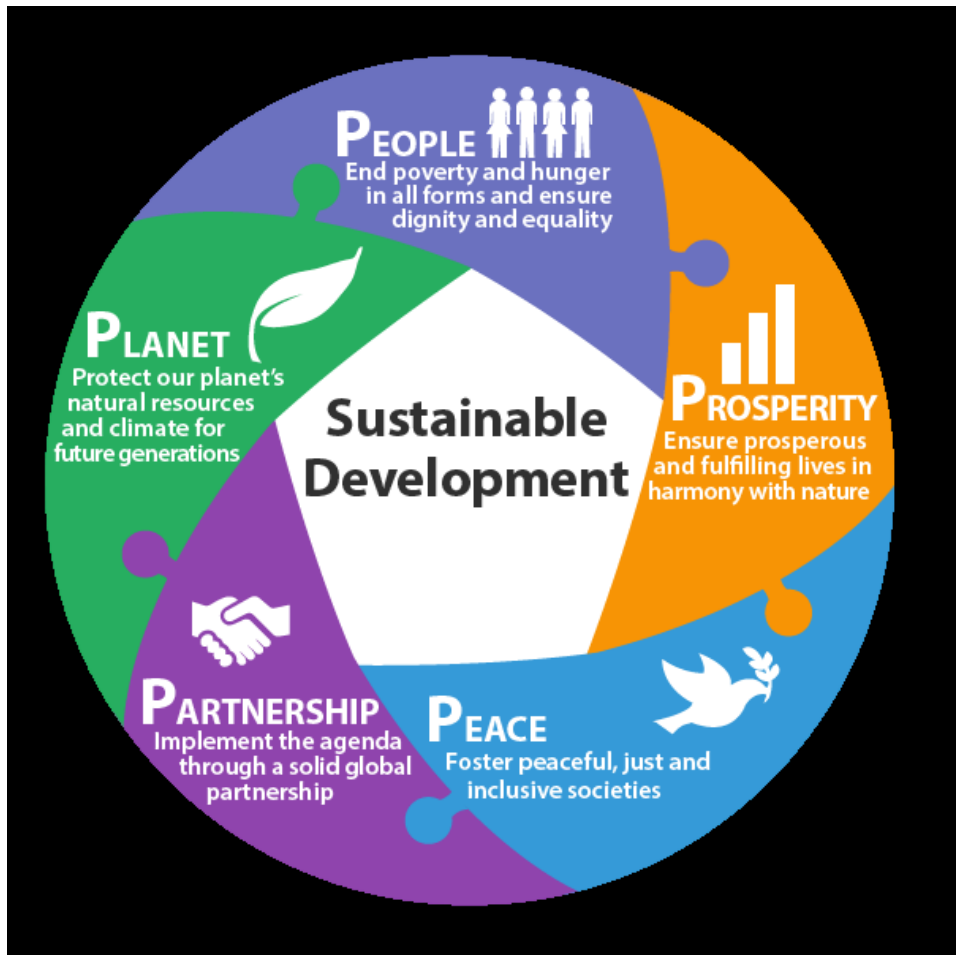

Figure 2:

Source: UNDP, Rawanda 


\section{India, SDGs and Smart Cities Mission}

India needs to adopt an approach that integrates the social, economic, and environmental dimensions and concerns which form the very foundation of sustainable development goals. To formulate such holistic, integrated approach; there is a need to develop strategy not only for the main 17 SDGs but for each of the 169 targets and proposed 304 indicators. Formulation of holistic, integrated strategies for achieving sustainable development goals will be different for each country. In case of India the Sustainable Development Goal number 11 of achieving Sustainable Cities will be very crucial in the light of its urbanization and Smart Cities Mission. The pillars of a smart sustainable city are also directly or indirectly aligned with the objectives of the SDGs. The closer the integration of sustainability into India's '100 Smart Cities' initiative, the greater will be the linkages with the SDGs.

\subsection{Urbanization: An inevitable outcome of Development Process}

Globally, more people live in urban areas than in rural areas. In 1950, $30 \%$ of the world's population was urban. Urbanization crossed 50\% threshold in 2008 and with $55 \%$ of the world's population residing in urban areas in 2018, by 2050, $68 \%$ of the world's population is projected to be urban (WUP 2018). Growth in the urban population is driven by overall population increase and by the upward shift in the percentage living in urban areas. Together, these two factors are projected to add 2.5 billion to the world's urban population by 2050, with almost $90 \%$ of this growth happening in Asia and Africa. Moreover, India, China and Nigeria - these three countries together are expected to account for $35 \%$ of the growth in the world's urban population between 2018 and 2050. India is projected to add 416 million urban dwellers, China 255 million and Nigeria 189 million. Cities account for the majority of GHG emissions and energy consumption across the globe. As cities are economic growth drivers in most of the nations, urbanization is projected to increase further in the near future. This, in turn, will drive the depletion of non-renewable resources as well as add to the extent of carbon dioxide emissions. To cope with rising urbanization and climate change issues, innovation and digital technology must be leveraged to minimize energy consumption and to improve

quality of life. Innovation must be combined with energy, digital technology and information and communications technology to address urbanization challenges and ensure sustainability. As already pointed earlier, the Sustainability covers not just the environmental aspect but also social equity and the economy.

India occupies $2.4 \%$ of the world area and supports more than $16 \%$ of the total world population. This clearly underlines the mismatch between the people and the resources. However the important issue is whether these many resources and the people are well balanced within India with reference to its urban and rural populations. According to the Smart Cities Mission Statement and Guidelines, 2015 by the Ministry of Urban Development, Government of India, "Cities are engines of growth for the economy of every nation, including India. Nearly $31 \%$ of India's current population lives in urban areas and contributes 63\% of India's GDP (As per Census 2011). With increasing urbanization, urban areas are expected to house $40 \%$ of India's population and 
contribute $75 \%$ of India's GDP by 2030 ". The economic growth and development of India over the years have changed the rural-urban set up tremendously. There has been a growing tendency of people to move to cities with the new opportunities that towns and cities generally provide. From the statistics provided earlier, the population ratio between the rural and urban is changing fast. We are becoming a nation of 'cities and towns'. The limited opportunities available in the rural set up and the mass prevalence of Unemployment and even underemployment have become a worrisome phenomenon in Indian villages. In the words of a villager, 'the village has become a dump with no good schools or hospitals or even cinemas. The attraction of cities with its thousand lights has become irresistible.' (STEP Reconceptualizing Smart Cities, 2015). By 2030 India may be far more urbanized than what is projected $(600$ million or $40 \%$ share of urban population) on the basis of the Census Report figures. A World Bank Report (September 2015) characterized India's urbanization process as " hidden" - because the share of India's population living in areas with urban-like features in 2010 stood at $55.3 \%$ (according to the Agglomeration Index). Going by these standards by 2030 India's Urban Population will be much more (more than 60 per cent). However, not a single Indian city is among the top 85 sustainable cities of the world.

The increasing percentage of urban population no doubt is an outcome of development process as such however many economists and social scientists have questioned whether it is real Urbanization or just the gathering of slums in Urban areas. This is because the growing urbanization must be on account of a gap between a decent quality of life available in cities due to their development in terms of health, hygiene, education, earnings, opportunities as compared to the rural counterparts. The Human Development in the cities ideally should be the guiding force for the rural people to migrate and settle down in cities. But the real issue is whether the development of our cities over the past years of economic planning had been sustainable or not. The answer is not very impressive. India's urbanization process is commented (WB Report 2015) as "messy" because 65.5 million Indians live in slums and 13.7 million below the poverty line (Census, 2011).This uncontrolled and expansive urbanization has been marked with significant gaps in urban infrastructure resulting in pressure on land, water supply and its quality, sewerage network services, disposal of solid waste, lack of open landscaped spaces, deterioration of public transport, resulting in environmental degradation and poor quality of urban life. Public transport accounts for only $22 \%$ of urban transport in India. 13 per cent of urban households do not have any form of latrine, less than 20 per cent of the road network is covered by storm water drainage and scientific disposal of solid waste is not there in most of the cities. There was a shortage of around 19 million dwelling units as per the 12th Plan.

On this background development of Integrated policies to improve the lives of both urban and rural dwellers are needed, strengthening the linkages between urban and rural areas and building on their existing economic, social and environmental ties.

Overpopulation, excessive consumption, pollution, and depletion of resources have presented environmental and health challenges in major cities. Many Indian cities are plagued with various environmental, social and economic issues such as resource scarcity, congestion, pollution, poverty, lack of affordable housing, proliferation of informal dwelling, as well as sewerage and sanitation problems. In short, urbanization is 
placing an environmental load on natural resources as cities account for $60-80 \%$ of energy consumption across the globe and for more than $70 \%$ of worldwide carbon dioxide emissions. Therefore there is a need for comprehensive development of physical, institutional, social and economic infrastructure within and across the cities. And this is crucial from the fact mentioned above that this $40 \%$ of India's urban population would be contributing to $75 \%$ of India's GDP by 2030 . This calls for a holistic approach which seems to be very important in improving the quality of life and attracting people and investments to the Cities, with a Virtuous cycle of growth and development. In order to provide better living conditions for existing and future generations, cities need to be improved by adopting the smart route and at the same time focussing on the sustainability aspect. This is because; Sustainable urbanization is a key to successful development.Development of Smart Cities Mission launched in 2014 in India is a step in this direction.

\subsection{SDGs \& Smart Cities Mission (SCM) in India}

India gave a commitment to implement SDGs in September 2015. The Prime Minister Narendra Modi affirmed a commitment to "make our cities smart, sustainable and engines of progress" by 2030. This builds on earlier promises of ending poverty, providing housing and basic services to all by the early 2020s. Out of the total 17 SDGs, nearly half of them (Goal number 1,2,3,6,7,8,9,11,12 and 13) can be achieved if the goal of Sustainable Smart Cities is achieved.

Smart cities, is not an Indian or Swadeshi concept. The idea was developed in the 2000s in high income countries of Europe, East and South-east Asia. These countries had wellestablished physical and digital infrastructure, high levels of urbanization. These countries consolidated their position as advanced markets and innovation-led economies. This state-led policy drive was given additional fillip by transnational corporations, seeking to reinvent themselves around the fourth industrial revolution, based on the Internet of Things (IoTs) that they believe could form a new digital substrate for $21 \mathrm{st}$ century cities. Much of the hype around smart cities in India is led by these firms seeking state support and possibly subsidies to expand market opportunities, in an era of uncertain growth in economies belonging to the Organisation for Economic Development and Cooperation (OECD).

This mission is very ambitious as making a city smart is a subjective concept as it would change country specific. There is no single model of a sustainable city, rather they are a choice of different solutions designed to support long-term ecological balance in that city and also across such cities. According to the World Bank's Sustainable Cities Framework, 'Sustainable cities (SC) can be understood as resilient cities that can more readily adapt to, mitigate, and promote economic, social, and environmental change. Sustainable development encompasses all aspects of a city's healthy development and should be done with a triple bottom-line in economic/financial, social, and environmental issues.'

PwC's smart city concept states that: 'Smart cities leverage technology and utilize existing and planned infrastructure investments to provide a higher quality of living to residents, a conducive investment climate for businesses and allow to optimize resources and transparency for governments. They can be considered for organic integration of 
systems, IT infrastructure, physical infrastructure, social and business infrastructure. These systems work collectively to generate actionable and intelligent information for decision makers.'

A Smart city in an Indian context is a bunch of a wishes' list of infrastructure, services, interconnectivity, geo-political factors and so on which directly or indirectly would aim at an ideal urban ecosystem in terms of four pillars of holistic development: institutional, physical, social and economic. In the approach to the Smart Cities Mission, the objective is to promote cities that provide core infrastructure and give a decent quality of life to its citizens, a clean and sustainable environment and application of 'Smart' Solutions. The focus is on sustainable and inclusive development and the idea is to look at compact areas, create a replicable model which will act like a light house to other aspiring cities (Smart Cities Mission Guidelines, 2015). In Indian context therefore, a Smart Sustainable City encompasses the following.

Table 1: Major Components of Smart Sustainable City

\begin{tabular}{|l|l|l|}
\hline Economic Progress & Environmental Progress & Social Development \\
\hline Competitive economy & $\begin{array}{l}\text { Climate change mitigation } \\
\text { and adaptation }\end{array}$ & Social inclusion, \\
\hline $\begin{array}{l}\text { Employment growth } \\
\text { and opportunity }\end{array}$ & $\begin{array}{l}\text { Water, waste and solar energy } \\
\text { management }\end{array}$ & Human rights \\
\hline $\begin{array}{l}\text { Affordable housing, } \\
\text { efficient urban mobility }\end{array}$ & Green buildings & $\begin{array}{l}\text { Sanitation, public health and } \\
\text { safety }\end{array}$ \\
\hline Governance & Sustainable transport & $\begin{array}{l}\text { Stakeholder engagement and } \\
\text { participation }\end{array}$ \\
\hline $\begin{array}{l}\text { Incubators, skill } \\
\text { development } \\
\text { centres, }\end{array}$ & Water and air quality & $\begin{array}{l}\text { Recreation: arts, sports, } \\
\text { Entertainment } \\
\text { Urban Planning }\end{array}$ \\
\hline $\begin{array}{l}\text { specialized business } \\
\text { parks, hubs, etc }\end{array}$ & $\begin{array}{l}\text { Natural resource management, } \\
\text { including biodiversity and green cover }\end{array}$ & $\begin{array}{l}\text { Smart healthcare and } \\
\text { education }\end{array}$ \\
\hline
\end{tabular}

Thus a Smart City according to Oxfam Living, Australia aims at a greater Access to public resources, such as quality education, safe health centres, easy access to public transportation, garbage collection services, safety and good air quality, telecommunications, parks, insurance, and buildings too. The Renovation of public spaces is another fundamental characteristic of sustainable cities. Public streets, squares, parks, urban spaces as well as modern irrigation and waste management practices are vital aspects of sustainable living. This would ensure the efficient use of energy and water, reducing their waste to the minimum. The reduction of $\mathbf{C O} 2$ and other Green House Gases (GHGs) harmful to the ozone layer is perhaps the most significant measure of a cities environmental commitment. Lowering CO2 levels can be achieved through the long-term shift towards new renewable energy sources, alternative means of transport such as bicycles, trains and electric buses and household commitment to water and energy saving. It is now well understood and documented too that overconsumption leads to excessive depletion of natural resources, greater waste and harmful by-products from the manufacturing process. Therefore it is critical that sustainable cities must promote and encourage ethical consumption, local food production and 
consumption to support local supply chains/ sources that would be more environmentfriendly. Sustainable city must raise awareness about the importance of recycling, reusing and reducing unwanted and irresponsible consumption among its citizens. The conceptual framework of the SCM in India is very much impressive but it is full of challenges due to the fact that India is not a high-income country with well-established infrastructure, markets and responsive public institutions. It would therefore be difficult compare itself with 'smart urbanism' like Seoul and Singapore.

\section{Challenges to SCM in India}

Most Indian cities continue to struggle with poverty; weak infrastructure and poor services; dysfunctional land and informal labour markets; fragmented governance; and feeble public participation in everyday governance, in what is otherwise an active, vigorous and contested democracy. In view of this a basic question is whether to address these questions arising out of development process itself or to develop our own models of swadeshi city-wide smart initiatives which can help our cities leapfrog to a more sustainable development pathway defined by the SDGs. The SDGs provide a wide and holistic development framework to encompass India's urban challenges. This ranges from ending poverty and hunger, to the provision of universal health care and education, housing and basic services, jobs and industrialization. All within local and global ecological limits and the strong commitment to reduce inequality and enable gender equality.

The major challenges can be listed as follows:

- Climate change and Carbon emissions: The reduction of CO2 and other Green House Gases (GHGs) harmful to the ozone layer is perhaps the most significant measure of a cities' environmental commitment.

- Unwarranted consumption and production: It is now well understood and documented too that over-consumption leads to excessive depletion of natural resources, greater waste and harmful by-products from the manufacturing process. The consumption as well as the production of goods and services have been unethical on account of wastage by few against the deprivation for masses who are socio-economically highly vulnerable sections.

- Human development: The increasing percentage of urban population no doubt is an outcome of development process, however many economists and social scientists have questioned whether it is real Urbanization or just the gathering of slums in Urban areas. This is because the growing urbanization must be on account of a gap between a decent quality of life available in cities due to their development in terms of health, hygiene, education, earnings, opportunities as compared to the rural counterparts. The Human Development in the cities ideally should be the guiding force for the rural people to migrate and settle down in cities. But Indian cities represent a paradox of educated elites with mass illiteracy and poverty. Overpopulation, excessive consumption, pollution, and depletion of resources have placed environmental and health challenges in major cities.

- Lack of greater access to Public resources: A Smart City requires greater Access to public resources, such as quality education, safe health centres and public transportation. However major Indian cities are far behind the desired access to public 
resources.

Bringing together various forms of citizen-centric development, inclusive, responsive and smart institutions and digital infrastructure, strategic e-governance to deliver the SDGs is a win-win for most stakeholders. The real challenge in India lies in the smartness of the implementation of the Mission. With an emphasis on smart governance, the SCM has the potential to be the blueprint for a new era of governance systems in the country. However the challenge of the SCM is developing a competitive federalism in Indian policymaking. Moreover, the element of self-evaluation and consequent project proposals for development and transformation of the city provide greater freedom to the city to decide personal goals for the SCM, overturning the rather static ideas of Centrebased policy schemes for urbanization.

\section{Conclusions and Suggestions:}

A smart sustainable city, thus, is a holistic city with multiple themes or components to ensure easy service delivery and quality life for citizens. The three pillars of sustainable economic advancement, political participation and social emancipation are the core foundations of a smart sustainable city. The real challenge is of making Smart Cities sustainable, for which emphasis on the SDGs, including those on inequality, participatory governance and climate change is the top most priority. The Digital India platform can be used to connect the dots between smart cities and the SDGs. The Digital India mission is a missing link that could help connect the Smart Cities mission to these high-level SDG outcomes, especially the Sustainable Cities goal to "make cities inclusive, safe, resilient and sustainable". The smart city guidelines stipulate that the Indian smart city needs to adhere to 24 features in order to be "smart". With an emphasis on promoting civic engagement and strengthening participatory local governance, the New Urban Agenda as reflected in SCM mirrors the commitment of the smart city for civic participation-where the citizens of the city have been involved in the mission at every step through polls and calls for suggestions to redevelop their cities. This would be real inclusivity and owning the development process by the citizens. We propose major suggestions in this regard as follows

- Engaging citizens for governance: Citizens are the pillars of a nation as they choose a government and all governance policies, laws and regulations are focussed on them. Participatory governance focuses on the democratic engagement of citizens to improve citizen participation in governmental policies and provides a platform for citizengovernment interaction that improves service delivery and inculcates social inclusiveness. The governance finally would make a difference for a Smart city.

- Active involvement of the private sector: Businesses are expected to develope new and innovative technological solutions and services. Innovative start-ups and local players can play a critical role. Public-private partnership (PPP) has been the preferred route for developing smart and sustainable city projects around the world. This can work for India too.

- Tapping innovative financial sources: The Indian government's smart city initiative has specified several possible funding sources-both conventional as well as 
innovative, in order to meet the 7.5 trillion INR amount required

over 20 years. Besides central and state funding, even the funding from multi-lateral and bilateral development agencies, other innovative financial instruments such as municipal bonds, infrastructure investment bonds, access to the Green Climate Fund (GCF) of the United Nations Framework Convention on Climate Change (UNFCCC) for climate change mitigation and adaptation projects must be encouraged to achieve Smart and sustainable cities. NABARD has taken an initiative in this regard, similarly the CSR too can contribute in SCM.

- Access to universal public services, using digital platforms and citizen awareness to improve infrastructure planning, management and services will lead to improved quality of urban life. More buoyant informal and formal labor markets by better digital matching of skills with work opportunities, wages and social protection will lead to more opportunities for decent work and in time, can lower poverty.

- Lowering CO2 levels can be achieved through the long-term shift towards new renewable energy sources like solar and wind energy where India had already attracted heavy investments. Alternative means of transport such as bicycles, trains and electric buses and household commitment to water and energy saving are the most needed.

- Sustainable cities must promote and encourage ethical consumption, local food production and consumption to support local supply chains/ sources that would be more environment- friendly.

- Sustainable city must raise awareness about the importance of recycling, reusing and reducing unwanted and irresponsible consumption among its citizens.

- Universal coverage of JAM (Jan Dhan-Aadhaar-Mobile) and moving to digital cash, lowering transaction costs and greater productivity of informal and formal enterprises can be accelerated.

- The coverage and the implementation of earlier ambitious schemes like Jawaharlal Nehru National Urban Renewal Mission (JNNURM) and Providing Urban Amenities to Rural Areas (PURA) would be broadened and strengthened.

Thus the SCM in India is a comprehensive tool for community's sustainability and for providing future generations with environmental, economic and social resources that meet our needs without compromising that of the future generations, as implied in the Intergenerational issues of Sustainable Development.

\section{References}

Aromar Revi (2016): How can we enable smart and sustainable cities? https//. www.livemint.com

Daptardar and Gore (2013): Scaling up the Sustainable Development Through Green Financing in India. Copenhagen Conference Paper.

Daptardar and Iyer (2018): Smart City: A Path towards Sustainable and Holistic Urbanization. A National Conference Paper.

Oxfam Living (2017): Sustainable Cities and Eco cities, http:// oxfamliving-www.oxfam.org.au

Puja Mondal: Changing Paradigms of Development - Perspective \& Changes

PwC Report Making cities smart and sustainable September 2015

Ravikant Joshi (2017): Financing of Smart Cities, A conference paper at Pune.

Reconceptualizing Smart Cities: A Reference Framework for India by Center for Study of Science, Technology and Policy September, 2015 
Shamika Ravi \& Nirupama Jayaraman: (2017) Important Lessons for Smart Cities Mission in Mint

Smart city framework - Guide to establishing strategies for smart cities and communities by The British Standards Institution 2014.

Smart City Mission Statement \& Guidelines, June 2015 by Ministry of Urban Development, Government of India.

UNDP Report(2015): Sustainable Development Goals

UNDP Human Development Reports - Various Issues.

Various plan documents and Economic Surveys, Government of India. 